2020, Volume 14, International Conference Innovative Business Management \& Global Entrepreneurship (IBMAGE 2020), pages: 70-81 |

https://doi.org/10.18662/lumproc/ibmage2020/06

\section{Analysis and Evolution of Profit and Net Profit Margin in the Pharmaceutical Industry in Romania}

\author{
Izabela Diana HADA'*, \\ Mihaela Maria MIHALCEA²
}

${ }^{1}$ Ph.D. Student, „1 Decembrie 1918” University of Alba Iulia, România, izabela_hada@yahoo.com

2 Ph.D. Student, ,1 Decembrie 1918” University of Alba Iulia, România, miha.ela 89@yahoo.com

* Corresponding Author
Abstract: Profit is considered to be an important source of financing the financial activity of any economic entity. The main purpose of any activity is to make a profit. As a significant part of equity, employees can be remunerated from profit (as part of their profit share) and also shareholders/associations can be also remunerated in the form of distributed dividends. The appreciation of financial performance is closely linked to the ability to make a profit. In this sense, the main purpose of this article is to analyze and describe the evolution of profit and net profit margin, as an indicator of performance appreciation, for economic entities in the field of manufacture of basic pharmaceutical products in Romania. The basis of the analysis is the annual financial statements for a number of 46 entities for the period 1999-2018 (20 years). The results of the research show that, from the point of view of the evolution of the number of entities that register profit, we are witnessing an increase from 12 entities in 1999 to 23 entities in 2018. However, referring to the increase in the number of entities from a total of 17 in 1999 to 46 entities in 2018, we notice that in 2018 only half of them register a profit. The other half falls into the category of less performing entities due to losses. However, after a period of financial decline (2008-2009) we see a gradual increase in profits recorded by economic entities in the pharmaceutical industry in Romania.

Keywords: financial performance; profit; revenue; net profit margin; pharmaceutical field.

JEL Classification: G01, G10, G14, G19

How to cite: Hada, D. I., \& Mihalcea, M. M. (2020). Analysis and Evolution of Profit and Net Profit Margin in the Pharmaceutical Industry in Romania. In M. W. Staniewski, V. Vasile, \& A. Grigorescu (vol. ed.), Lumen Proceedings: Vol. 14. International Conference Innovative Business Management \& Global Entrepreneurship (IBMAGE 2020) (pp. 70-81). Iasi, Romania: LUMEN Publishing House. https://doi.org/10.18662/lumproc/ibmage2020/06 


\section{Introduction}

The pharmaceutical field as an economic sector is one of the most profitable and largest industries in the world, but it has not been protected from the global financial crisis and its harmful effects [14]. Economic entities seek to carry out profitable economic activities as a result of capitalizing on factors of production (the use of which generates an expense from an accounting point of view) in order to obtain results (based on income).

Profit is considered to be an important source of financing the financial activity of any economic entity. In this sense, the aim of this article is to analyze and describe the evolution of profit and net profit margin, as an indicator of performance appreciation, for economic entities in the field of manufacture of basic pharmaceutical products in Romania. The basis of the analysis is the annual financial statements for a number of 46 entities for the period 1999-2018 (20 years). The results of the research show that, from the point of view of the evolution of the number of entities that register profit, we are witnessing an increase from 12 entities in 1999 to 23 entities in 2018. However, referring to the increase in the number of entities from a total of 17 in 1999 to 46 entities in 2018, we notice that in 2018 only half of them register a profit. The other half falls into the category of less performing entities due to losses. However, after a period of financial decline (20082009) we see a gradual increase in profits recorded by economic entities in the pharmaceutical industry in Romania.

\section{Problem Statement}

Large pharmaceutical companies have been known as chair in development, sustainability, which means that the analysis of the evolution of their financial position can demonstrate the vanguard of sustainable corporate performance [1]. The biotechnology sector, but especially the pharmaceutical sector is among the most innovative subsection of industry in Europe [10]. According to international estimates, global pharmaceutical sales are projected to reach $\$ 1.17$ trillion by 2021, and the number of economic entities in the pharmaceutical industry will approach 316 thousand in 2019 [8].

An important research [16] in the pharmaceutical field focuses on evolution of the pharmaceutical sector in Romania for the period before the financial crisis and the period after the crisis. According to her, during the pre-crisis period between 2002 and 2007, the Romanian pharmaceutical market experienced a period of sustained growth, with an annual growth rate 
of $25 \%$, being stimulated by rapid economic development which led to an increase in financial resources, both public and private. The same quoted source claims that, starting with the second half of 2007, the pharmaceutical market has entered a period of stagnation of almost 3 years, and the reasons for this dynamic are mainly related to the negative effects of the recession on the financial resources of the pharmaceutical healthcare sector.

Profit is considered to be an important source of financing the financial activity of any entity. The main objective of any activity is to make a profit. As a significant part of equity, employees can be remunerated from profit (as part of their profit share) and also shareholders/associations can be also remunerated in the form of distributed dividends. The appreciation of financial performance is closely linked to the ability to make a profit. The economic theory of the entity implies the efficient use of available resources in order to obtain results, economic successes. Moreover, the competitive business environment determines managers to ensure optimal use of resources, regardless of the nature of their business [7]. Profit is the main element underlying the calculation and analysis of profitability. Profitability rates are determined as the ratio between two indicators depending on their type, comparing the effect with the effort made. Net profit tends to be the image of a long-term goal that quantifies market development, but especially the success of a product [11].

Assessing the financial situation of an economic entity involves measuring the results of managerial decisions, whether financial, economic, social, investment, lending, and development. Profitability is the ability of the economic agent to make a profit from its own activity and can be expressed by the return of economic profitability or the return of financial profitability, and the decrease in profitability is a signal to increase the risk of bankruptcy of the company [2]. A view of practitioners' possible performance measurement goals can be found in some authors research [5], which states that a although there is a large number of academic research on the evaluation of financial performance, all this research has addressed the issue of measuring performance, in the end they can't be used by practitioners in the field, which focuses on improving performance.

Financial performance uses several measurement tools in the form of financial reports to assess whether the company's objectives have been met, with several categories of financial reports, such as ROA, ROE and net profit margin [9].

The authors Carp A., and Mirea M. [3], in Profitability as a form of communication of the value of an entity that operates for profit, argue that the net profit margin, a financial indicator of profitability, highlights the proactivity of the total activity of a company in terms of percentage view. 
The higher the percentages, the more stable the company is and has a good financial situation in terms of productivity. The net profit margin indicator measures the profit obtained from the sale after deducting all expenses incurred - respectively operating expenses, direct expenses, interest expenses and income / income tax expenses; and a higher net profit margin meant that the firm was more profitable [6].

Net profit margin is calculated by:

$$
N P M=\frac{\text { Net income }}{\text { Sales }} * 100
$$

Approaches related to the indicators used in the activity of assessing financial performance are also found in some authors research's [4], who in their paper also make a brief foray into the indicators used by other researchers, so that some of this considers that the performance of an organization is a problem of substantiating managerial decisions with several attributes, which has been in the attention of many researchers. Some researchers used the net profit margin, return on capital, return on assets to measure financial performance by using 19 companies as the basis for research, other researchers used asset return as an indicator to assess financial performance and concluded that responsibility has a major impact on financial performance, and other researchers are also studying the relationship between financial performance and environmental management using two important indicators: return on capital and earnings per share (EPS) to measure the profitability of the business.

Srivastava A. [13] analyzing by using ratio the profitability of the best five pharmaceutical companies of India and determinate the Return on Equity (ROE), Net profit Margin (NPM), and Return on Assets (ROA). According to Atkinson et al. (1997) cited by Pintea M. [12] the performance measurement activity should support economic entities in understanding and evaluating the value received from suppliers, creditors and employees, the value provided by stakeholders and the effectiveness of the processes carried out within the economic entity and its strategic properties. Thus, we can appreciate that the complex activity of measuring performance plays the role of coordinating, evaluating, monitoring and diagnosing the activity of any entity.

\section{Research Questions/Aims of the research}

The main objective of this article is to analyze and describe the evolution of profit and net profit margin, as an indicator of performance appreciation, for a number of 46 economic entities in the field of manufacture of basic pharmaceutical products in Romania in the period 
1999-2018 (20 years). Based on the main objective, the following specific research objectives have been set based on the main objective. In this category we include: description of the pharmaceutical field and the performance of this field, illustration of the evolution of net and gross profit and most important, net profit margin for entities in the field of basic pharmaceutical products manufacturing in Romania, description of the importance of profit and net profit margin indicator measuring financial performance. In order to achieve the basic objective, we conducted a research on all entities in Romania whose object of activity is the manufacture of basic pharmaceutical products, 46 entities in total, according to the site www.topfirme.com [17]. The analyzed period includes the last 20 years (1999-2018). In the category of research hypotheses we include: profit is considered the most important indicator for measuring financial performance, along with net profit margin (a profitability indicator), the pharmaceutical sector has seen an increase in sales of pharmaceuticals in recent years. The paper is structured in two components: the first component includes the presentation of concepts related to profit, net profit margin, pharmaceutical sector, and the second is dedicated to the analysis and evolution of profit and net profit margin in Romania in the pharmaceutical sector for 1999-2018.

\section{Research Methods}

To achieve the research objectives, we used as research methods through: review of the literature, theoretical documentation, participatory observation, comparison, study of synthesis documents, graphic representation, operational research. By using specialized bibliographic references, we described the profitability of the pharmaceutical industry; we presented concepts related to profit, net profit margin, and important indicators of the activity of measuring financial performance. We have chosen as the method of scientific research and the method of studying the synthesis financial documents (of the financial reports / of the annual financial statements) for the basis of the analysis and evolution of profit and net profit margin in the Romanian pharmaceutical industry. The base of research is represented by 46 economic entities in the pharmaceutical industry, entities whose object of activity consists in the manufacture of basic pharmaceutical products, for which the gross and net profit and the net profit margin were analyzed over a period of 20 for years (1999-2018). The indicators were calculated based on the information contained in the financial statement of the analyzed entities, published on the mfinante.ro website [18]. For each year we determined the sales the gross / net profit, by 
summing up these indicators for each analyzed entity. Based on the total, we calculated the net profit margin. We chose graphical representation as a research method to outline the evolution in dynamics of the two indicators for assessing financial performance in the pharmaceutical industry. Participatory observation and substantiation of opinions based on the results were used to achieve the proposed objectives.

\section{Findings}

The Romanian pharmaceutical market, including prescription and over-the-counter drugs, increased by 13.4\% compared to 2017, in 2018 reaching the level of 3.374 billion euros, according to data provided by market research firm IMS in December and quoted by Zentiva, one of the leading local manufacturers of medicines [15].

In order to achieve the basic objective, we conducted a research on all entities in Romania whose object of activity is the manufacture of basic pharmaceutical products, 46 entities in total, according to the site www.topfirme.com. In the table below we find the situation of the total gross and net profit registered by the companies in the last 20 years (19992018):

Table no 1: Statement of gross and net profit, sales and net profit margin for entities in pharmaceutical fields in Romania in the period 1999-2018

\begin{tabular}{ccccc}
\hline Year & Gross profit & Net profit & Sales & NPM \\
\hline $\mathbf{1 9 9 9}$ & 6126904 & 5073791 & 62345886 & 8,14 \\
$\mathbf{2 0 0 0}$ & 9503911 & 7738297 & 98873582 & 7,83 \\
$\mathbf{2 0 0 1}$ & 23584910 & 19690103 & 155930457 & 12,63 \\
$\mathbf{2 0 0 2}$ & 22936356 & 18560097 & 194025162 & 9,57 \\
$\mathbf{2 0 0 3}$ & 28236847 & 22873947 & 208152236 & 10,99 \\
$\mathbf{2 0 0 4}$ & 30410590 & 23468803 & 301085366 & 7,79 \\
$\mathbf{2 0 0 5}$ & 36007447 & 30095716 & 325083131 & 9,26 \\
$\mathbf{2 0 0 6}$ & 63928665 & 54793557 & 410283900 & 13,36 \\
$\mathbf{2 0 0 7}$ & 40446417 & 34147798 & 519187395 & 6,58 \\
$\mathbf{2 0 0 8}$ & -3700222 & -8444247 & 589346290 & $-1,43$ \\
$\mathbf{2 0 0 9}$ & 36728557 & 29279099 & 616901989 & 4,75 \\
$\mathbf{2 0 1 0}$ & 66905278 & 54315433 & 714595680 & 7,6 \\
$\mathbf{2 0 1 1}$ & 37982926 & 21223919 & 768419756 & 2,76 \\
$\mathbf{2 0 1 2}$ & 83683722 & 70281417 & 802986221 & 8,75 \\
$\mathbf{2 0 1 3}$ & 97072525 & 84288217 & 852333156 & 9,89 \\
\hline
\end{tabular}


Lumen Proceedings 14 | International Conference IBMAGE 2020

\begin{tabular}{ccccc}
\hline $\mathbf{2 0 1 4}$ & 80818146 & 64642820 & 921183344 & 7,02 \\
$\mathbf{2 0 1 5}$ & 85201864 & 71817265 & 975129495 & 7,36 \\
$\mathbf{2 0 1 6}$ & 127919399 & 106928339 & 962412622 & 11,11 \\
$\mathbf{2 0 1 7}$ & 123537051 & 108885689 & 1043605605 & 10,43 \\
$\mathbf{2 0 1 8}$ & 144999859 & 129695300 & 1096414564 & 11,83 \\
\hline
\end{tabular}

Source: author's calculations starting from the information contained in the annual financial reports

In order to observe the dynamic evolution of gross and net profit, as well as the net profit margin in the graphs below (Chart no. 1 and Chart no. 2) we represented the evolution of these indicators at the entities in the pharmaceutical industry in 1999- 2018.

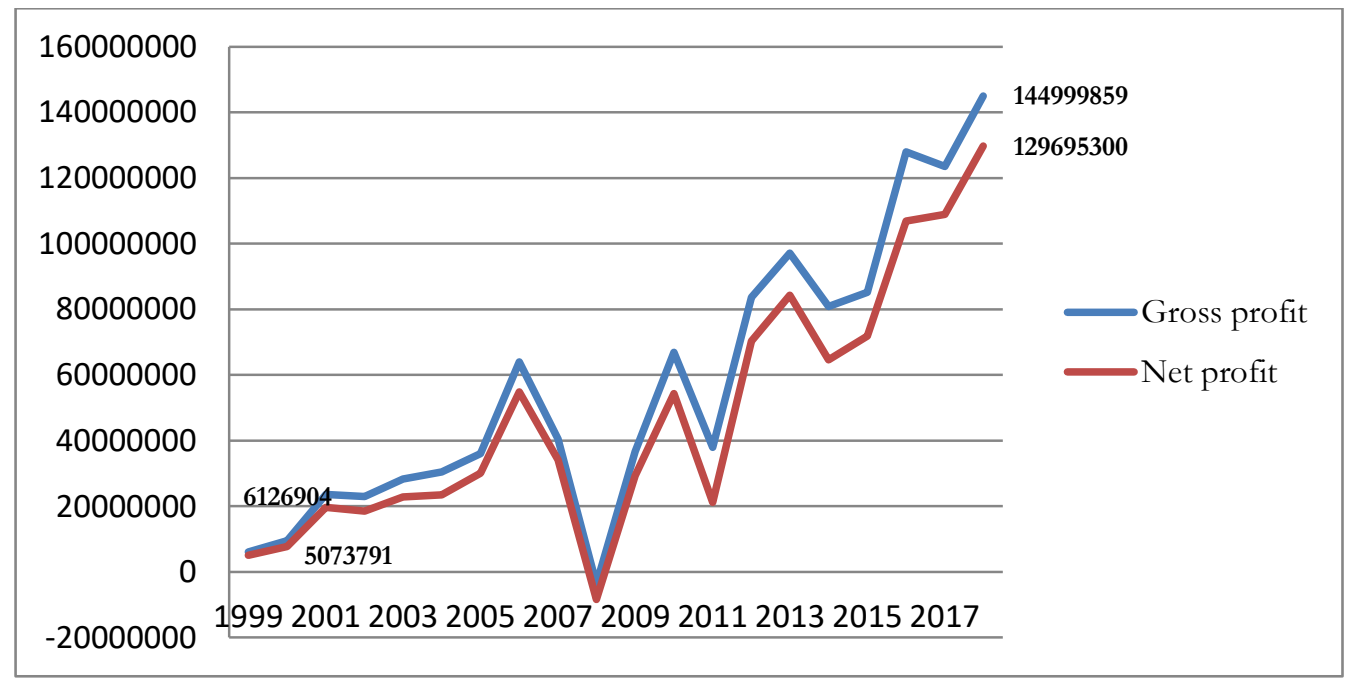

Graph no. 1. Evolution of gross profit and net profit for pharmaceuticals entities in the period 1999-2018

Source: author's calculations starting from the information contained in the annual financial reports

We observe an irregular evolution of both the net profit and the gross profit in the period 1999-2018 for the entities in the field of manufacturing basic pharmaceutical products in Romania. The financial crisis of 2008-2009 left a strong mark on the evolution of profit in the pharmaceutical industry. In 2008 we observe in the case of entities with Caen code 2110 a negative evolution compared to the 2007, strongly influenced by the increase of expenses in relation to the evolution of 
revenues. After a period of steady growth (1999-2006), the difficulties generated by the financial crisis of 2008 led the entities to a loss. However, in the last 18 years we observe fluctuating evolutions of net and gross profit either in the sense of increase $(2012,2013,2016,2018)$ or in the sense of decrease $(2011,2014,2017)$. However, during the 20 years we can discuss a positive evolution, in the sense of increasing the net profit from 5073791 in 1999 to 129695300 lei in 2018, and the gross profit from 6126904 lei to 144999859 lei in 2018.

below:

The evolution of the net profit margin is illustrated in the chart

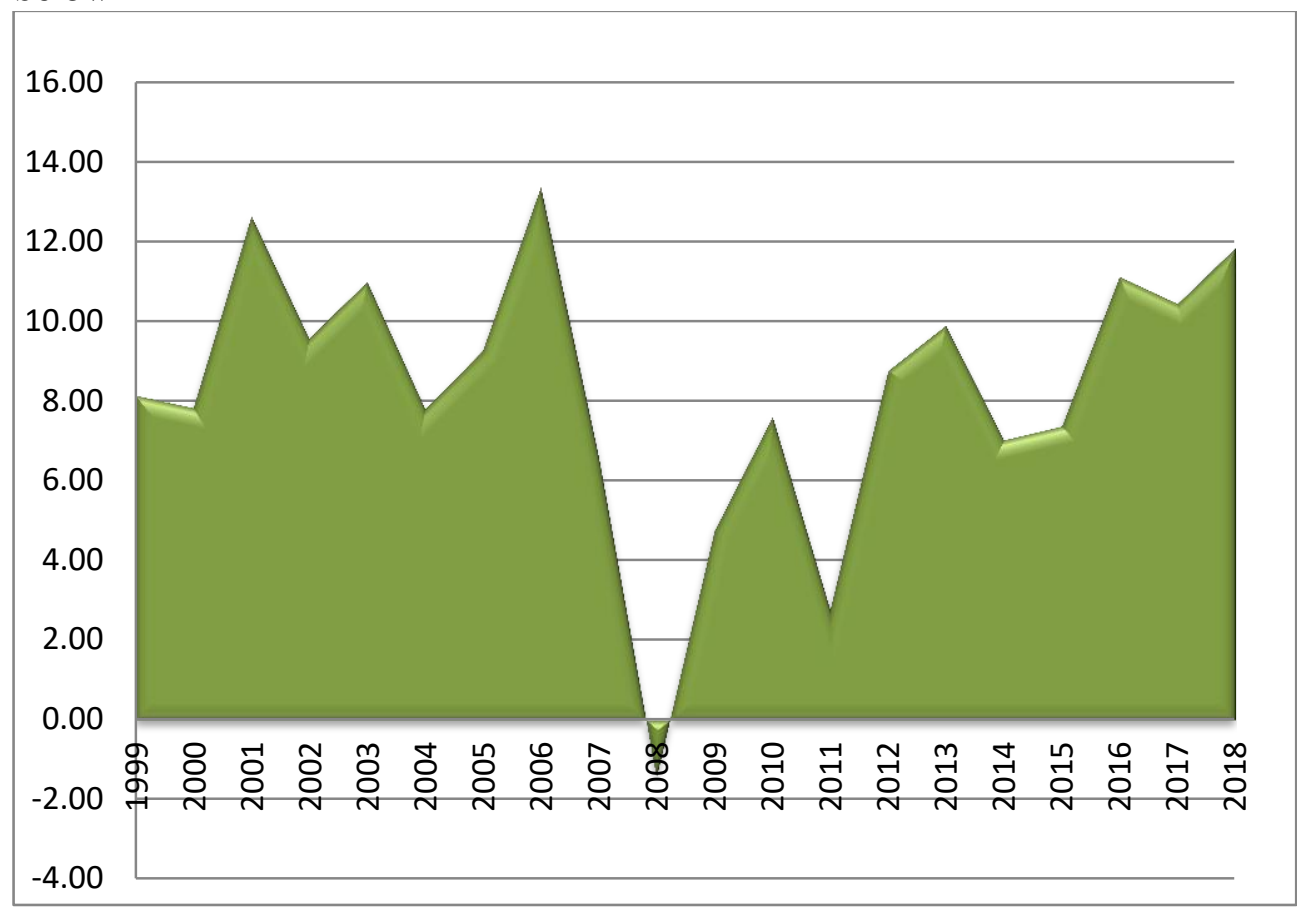

Graph no. 2. Evolution of net profit margin for pharmaceuticals entities in the period 1999-2018

Source: author's calculations starting from the information contained in the annual financial reports

Net profit margin fluctuates during the analysis period. As a result of the loss recorded by the entities in the field of manufacture of basic pharmaceutical products, in 2008 we observe a negative value of the net profit margin. The highest value of the net margin is recorded in 2006.

We consider it necessary to present a ranking of the 46 entities in the pharmaceutical sector according to the value of net profit. Thus, in the chart 
below we find the share of entities that recorded a loss, a profit equal to zero, as well as a positive profit.

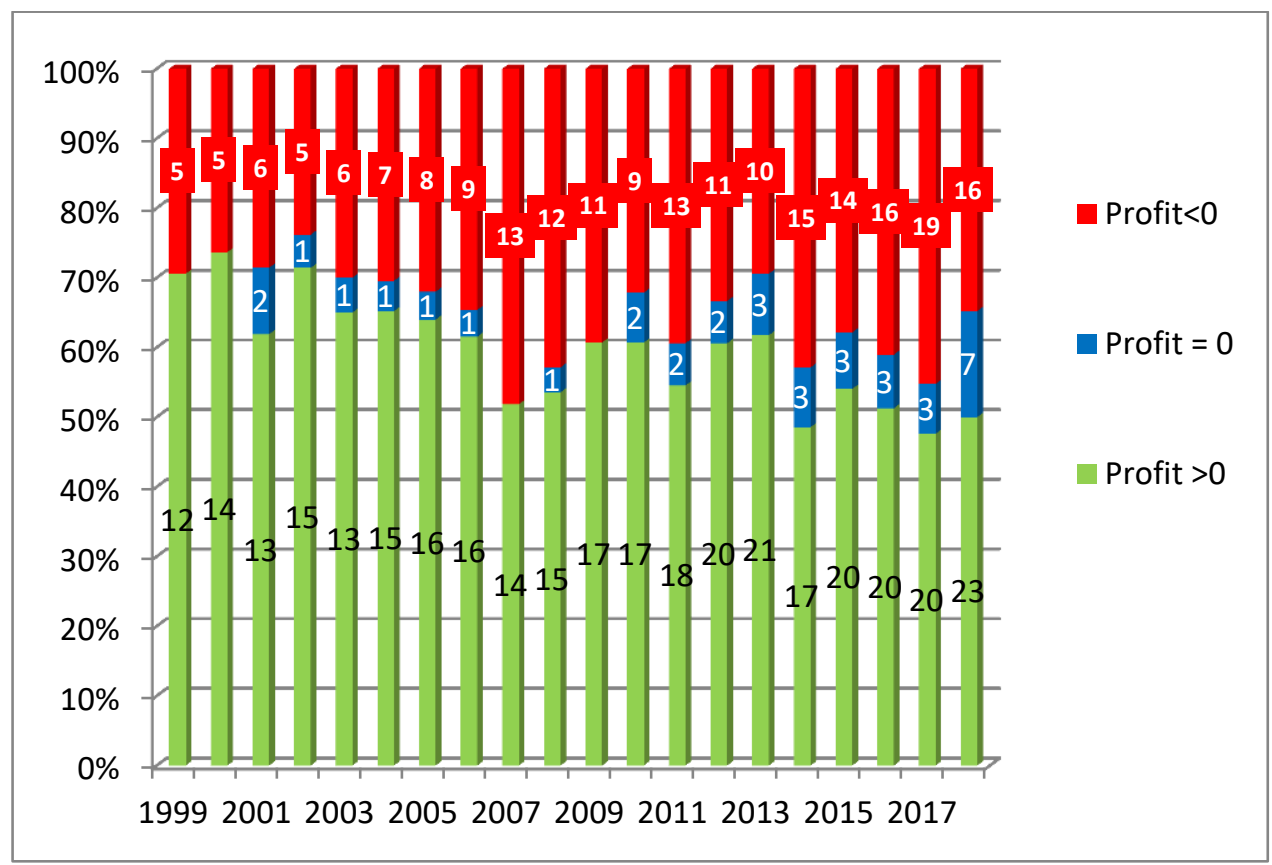

Graph no. 3. Ranking of entities in the pharmaceutical sector according to the value of profit in the period 1999-2018

Source: author's calculations starting from the information contained in the annual financial reports

During the analyzed period we notice that we have a relatively small number of entities that register a profit equal to zero. Starting with 2001, their number increased from 2 entities to 7 entities in 2018. From the point of view of the evolution of the number of entities that register profit, we can say that we stopped at an increase from 12 entities in 1999 to 23 entities in 2018. However, referring to the increase in the number of entities from a total of 17 in 1999 to 46 entities in 2018, we note that in 2018 only half of them are profitable. The other half falls into the category of less performing entities due to losses. The number of entities that obtained a loss increased significantly from 5 to 17 in 2018. 


\section{Discussions}

Profit is an important indicator of appreciation of financial performance. However, the information related to this indicator contained in the entities' annual financial statements may be easily influenced by management interests. Creative accounting plays an important role in profit management. In a future research we aim to analyze the implications of creative accounting on the profit of economic entities in the pharmaceutical industry in Romania.

\section{Conclusions}

The pharmaceutical industry as an economic sector is one of the most profitable and largest industries in the world, but it has not been protected from the global financial crisis and its harmful effects [14]. According to international estimates, global pharmaceutical sales are projected to reach $\$ 1.17$ trillion by 2021 , and the number of economic entities in the pharmaceutical industry will approach 316 thousand in 2019 [8]. An important research [16] in the pharmaceutical field focuses on the evolution of the pharmaceutical field in Romania for the period before the financial crisis and the period after the crisis. According to her, during the pre-crisis period between 2002 and 2007, the Romanian pharmaceutical market experienced a period of sustained growth, with an annual growth rate of $25 \%$, being stimulated by rapid economic development which led to an increase in financial resources, both public and private. The same quoted source claims that, starting with the second half of 2007, the pharmaceutical market has entered a period of stagnation of almost 3 years, and the reasons for this dynamic are mainly related to the negative effects of the recession on the financial resources of the pharmaceutical healthcare sector.

Profit is considered to be an important source of financing the financial activity of any entity. The main objective of any activity is to make a profit. As a significant part of equity, employees can be remunerated from profit (as part of their profit share) and also shareholders/associations can be also remunerated in the form of distributed dividends. The appreciation of financial performance is closely linked to the ability to make a profit.

In this sense, the objective of this article is to analyze and describe the evolution of profit and net profit margin, as an indicator of performance appreciation, for economic entities in the field of manufacture of basic pharmaceutical products in Romania. The basis of the analysis is the annual financial statements for a number of 46 entities for the period 1999-2018 (20 years). The results of the research show that, from the point of view of the evolution of the number of entities that register profit, we are witnessing an 
increase from 12 entities in 1999 to 23 entities in 2018. However, referring to the increase in the number of entities from a total of 17 in 1999 to 46 entities in 2018, we notice that in 2018 only half of them register a profit. The other half falls into the category of less performing entities due to losses. However, after a period of financial decline (2008-2009) we see a gradual increase in profits recorded by economic entities in Romania in the pharmaceutical field.

\section{References}

[1] Barbuta MN. The Effect of Leverage on Profitability of Pharmaceutical Companies. Economics and Applied Informatics, "Dunarea de Jos" University of Galati, Faculty of Economics and Business Administration. 2013;1:45-52.

[2] Burja C. Economic-financial analysis: methodological aspects and practical applications. Cluj-Napoca: Casa Cărții de Ştiință Publishing House; 2009.

[3] Carp A, Mirea M. Profitability as a form of communication of the value of an entity that operates for profit. Romanian Statistical Review. 2017;Sup6: 184-191.

[4] Deng Y, Zou S, You D. Financial performance evaluation of nuclear powerrelated enterprises from the perspective of sustainability, Environmental Science and Pollution Research. 2020;27:1-15. 10.1007/s11356-019-07545-1.

[5] DeNisi AS, Pritchard R. Performance Appraisal, performance management and improving individual performance: a motivational framework. Management and Organization Review. 2006;2(2):253-277.

[6] Dita AH, Murtaqi I. The effect of net profit margin, price to book value and debt to equity ratio to stock return in the Indonesian consumer goods industry. Journal of Business and Management. 2014;3(3):305-315.

[7] Ejike SI, Agha NC. Impact of Operating Liquidity on Profitability of Pharmaceutical Firms in Nigeria. International Journal of Academic Research in Accounting, Finance and Management Sciences, Human Resource Management Academic Research Society, International Journal of Academic Research in Accounting, Finance and Management Sciences. 2018;8(3):73-82.

[8] Fenyves V, Nyul B, Dajnoki K, Bacs Z, Tomori G. Profitability of Pharmaceutical Companies in the Visegr $\tilde{A}_{j} \mathrm{~d}$ Countries. Montenegrin Journal of Economics, Economic Laboratory for Transition Research (ELIT). 2019;15(4):99-111.

[9] Khajar I, Hersugondo H, Udin U. Privatization and financial performance: evidence from Indonesia.Quality. 2019;20(173):107-110. 
[10] Kolodziejka K. Pharmaceutical sector in the new reimbursement era. Management. 2012;16(1):203-215.

[11] Nishanthini A, Nimalathasan B. Determinants of Profitability: A Case Study of Listed Manufacturing Companies in Sri Lanka. Journal of Management. 2013;VIII(1):42-50.

[12] Pintea MO. Performance evaluation: literature review and time evolution. Annals of Faculty of Economics, University of Oradea, Faculty of Economics. 2012;1(1):753-758.

[13] Srivastava A. Diagnosing inter firm profitability of pharmaceutical industry: an empirical analysis for India. Technology Science Journal. 2017;9(9):32-36.

[14] Stănică FA, Străchinaru AI, Ilie V. Influences on the profitability of the pharmaceutical industry in Romania. Theoretical and Applied Economics, Asociatia Generala a Economistilor din Romania - AGER. 2015;0(Special I):97-105.

[15] Stog I., The Romanian pharmaceutical market increased by $13.4 \%$ in 2018 , to 3.4 billion euros, [Internet], 2019, Available from: https://www.wallstreet.ro/articol/Companii/240670/piata-farmaceutica-din-romania-acrescut-cu-13-4-in-2018-la-3-4-miliarde-euro.html

[16] Institutul de Prognoză Economică. The pharmaceutical industry in Romania: the main trends and the impact on society and the economy [Internet]. [Updated February 2012]. Available from: http://www.lawg.ro/files/assets/userfiles/files/Industria \%20Farmaceutica $\% 20$ din $\% 20$ Romania.pdf

[17] Top Firme [Internet]. Available from: www.topfirme.com

[18] Ministerul Finanțelor Publice [Internet]. Available from: www.mfinante.ro 